\title{
Communities of practice as a solution for the implementation gap in internationalisation of the curriculum.
}

\author{
Deirdre Ryan \\ Technological University Dublin, deirdre.ryan@tudublin.ie \\ Fiona Faulkner \\ Technological University Dublin, fiona.faulkner@tudublin.ie \\ Robert Flood \\ Technological University Dublin, robert.flood@tudublin.ie
}

See next page for additional authors

Follow this and additional works at: https://arrow.tudublin.ie/creaart

Part of the Educational Assessment, Evaluation, and Research Commons, and the Higher Education Commons

\section{Recommended Citation}

Ryan, D., Faulkner, F., Dillane, D., \& Flood, R. V. (2021). Communities of practice as a solution for the implementation gap in internationalisation of the curriculum. Higher Education Research \& Development, 1-16. DOI: $10.1080 / 07294360.2021 .1877630$

This Article is brought to you for free and open access by ARROW@TU Dublin. It has been accepted for inclusion in Articles by an authorized administrator of ARROW@TU Dublin. For more information, please contact arrow.admin@tudublin.ie, aisling.coyne@tudublin.ie, gerard.connolly@tudublin.ie.

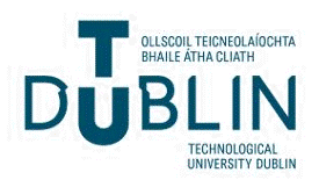




\section{Authors}

Deirdre Ryan, Fiona Faulkner, Robert Flood, and Dominic Dillane 


\section{Communities of practice as a solution for the implementation gap in internationalisation of the curriculum}

\section{Deirdre Ryan, Fiona Faulkner, Dominic Dillane \& Robert V. Flood}

To cite this article: Deirdre Ryan, Fiona Faulkner, Dominic Dillane \& Robert V. Flood (2021): Communities of practice as a solution for the implementation gap in internationalisation of the curriculum, Higher Education Research \& Development, DOI: 10.1080/07294360.2021.1877630

To link to this article: https://doi.org/10.1080/07294360.2021.1877630

\section{Published online: 03 Feb 2021.}

Submit your article to this journal 둔

山ll Article views: 286

Q View related articles $\sqsubset$

View Crossmark data \lceil

Citing articles: 1 View citing articles $๘$ 


\title{
Communities of practice as a solution for the implementation gap in internationalisation of the curriculum
}

\author{
Deirdre Ryan (D), Fiona Faulkner, Dominic Dillane and Robert V. Flood \\ School of Hospitality, Management \& Tourism, Technological University Dublin, Dublin 1, Ireland
}

\begin{abstract}
The educational benefits of internationalisation in higher education are of paramount importance for all students. Despite an increasing presence of best practice guides and internationalisation strategies, there appears to be a significant implementation gap in terms of lecturers' engagement with internationalisation in their teaching practice. Through an Action Research-informed Community of Practice approach, this study aims to provide new insights into lecturers' engagement with Internationalisation of the Curriculum by examining their own perspectives, an area which has been underdeveloped to date.

The Community of Practice provided an effective way of raising lecturers' awareness of Internationalisation of the Curriculum, while simultaneously effecting change at teaching and institution-wide levels. It facilitated an environment that encouraged lecturers to both incorporate global dimensions into their teaching and collaborate with colleagues to provide integrated learning opportunities for students that reflect the multicultural world.

The findings presented focus specifically on lecturers' perspectives of Internationalisation of the Curriculum and are relevant to a large body of stakeholders, namely those involved in Internationalisation of the Curriculum specifically, as well as practitioners interested in Continuous Professional Learning and best practice teaching in general.
\end{abstract}

ARTICLE HISTORY

Received 8 July 2020

Accepted 14 December 2020

\section{KEYWORDS}

Internationalisation of the

Curriculum; Lecturers' perspectives; Community of Practice; Change theory; Continuous Professional Learning

\section{Introduction}

Internationalisation in the higher education (HE) context has been a subject of discussion and prevalent in research in recent years due to its associated cultural, educational and economic benefits (DoES, 2016). Higher Education Institutions (HEIs) must recognise the importance of Internationalisation of the Curriculum (IoC) and provide the necessary supports in order to leverage the positive effects of the increasing cultural diversity in HE and to ensure it is a long-term, sustainable process (Ryan et al., 2019).

While there is an increasing presence of internationalisation strategies in government and institutional policies, there seems to be an implementation gap between the theory and practice surrounding the internationalisation of HE. The most significant impediment for successful implementation of IoC appears to be a lack of lecturer engagement and yet there is a shortage of research that takes a stakeholder approach to further 
understand this engagement and the inherent implementation gap (Clifford \& Montgomery, 2011; Green \& Whitsed, 2015; Leask, 2011, 2013). More specifically, there is little research in the Irish HE context as Ireland is still in a relatively early stage of the internationalisation process, focusing particularly on student recruitment (Clarke et al., 2018). The study was conducted in three Institutes of Technology, which recently merged to form Technological University Dublin (TU Dublin). One of the distinguishing features of the TU is that it aims be a globally engaged university (DTUA, 2014).

The aim of this study is to examine lecturers' engagement with IoC and the inherent implementation gap by establishing a cross-disciplinary IoC: Community of Practice $(\mathrm{CoP})$ in TU Dublin. Volunteers were requested to participate in an IoC: CoP in an endeavour to empower a culture of support for IoC and embed internationalisation into T\&L. The following research questions (RQs) guided the study:

In the context of Irish HEIs and from the lecturers' perspectives:

(1) To what extent do lecturers understand and engage with the concept of IoC?

(2) If lecturers are not engaging with IoC, why is this the case in spite of an increasing presence of internationalisation in Government and HEI policy documents and an increasing number of IoC guides?

(3) To what extent can a CoP, underpinned by Change Theory, influence lecturers to internationalise their curricula and what changes, if any, might arise at an individual, T\&L and institution wide level, as a result?

Initial findings and analysis of the IoC: $\mathrm{CoP}$ process are discussed and their implications for both policy and practice are outlined.

\section{Implementation of internationalisation of the curriculum}

IoC, which sits under the general term of Internationalisation of $\mathrm{HE}$ and supports a comprehensive approach to the topic, is defined as follows:

Internationalisation of the Curriculum is the incorporation of an international and intercultural dimension into the content of the curriculum as well as the teaching, learning and assessment arrangements and support services of a programme of study. (Leask, 2009, p. 209)

IoC is contextual in nature and different disciplines will interpret it in different ways. However, at its core an internationalised curriculum has three key tenets, namely, global perspectives, intercultural competencies and global citizenship (Clifford, 2013). These attributes could be incorporated into the curriculum content, T\&L strategies and assessment to varying degrees.

IoC is of significant importance for both domestic and international students. In addition to ensuring curricula are inclusive and attractive to students from diverse cultures, it also ensures curricula equip all students with the skills and attributes to live and work competently and ethically in a multicultural world (Jones, 2010).

By responding to the cultural diversity that is present in contemporary education, IoC inspires innovations in T\&L (Leask, 2011, 2013). This results in a more meaningful education for the whole student cohort. IoC ensures the cultural diversity is utilised as a 
teaching resource and also fosters a classroom environment that is reflective of the global workplace (Hellsten, 2007).

Through incorporating global dimensions into the education system, IoC cultivates a greater appreciation of international events and perspectives. It equips students with twenty-first century graduate attributes such as global citizenship and intercultural competencies which are integral to success (Henard et al., 2012).

From the literature, it is evident that lecturers' lack of engagement appears to be the most significant obstacle for successful implementation of IoC (Leask, 2013). This is attributed to a number of factors, interalia, lecturers' lack of awareness of internationalisation, lack of IoC-related Continuous Professional Learning (CPL) and the fact that IoC is a transformational change. The lack of awareness stems from ambiguity surrounding the terminology and a lack of familiarity with international students' needs and learning backgrounds as the practicalities of internationalisation have not typically been discussed with lecturing staff. Furthermore, while lecturers are central to realising the change, their voices have not been prioritised to date (Kirk et al., 2018; Leask, 2013). While studies to date have clearly outlined the benefits of IoC, there is a scarcity of studies that prioritise the engagement piece (Clarke et al., 2018; Hoff \& Gobbo, 2019). There is a need for HEIs to treat IoC as a transformational change and provide the necessary supports to engage lecturers with the practice.

\section{Internationalisation is a transformational change}

Internationalisation addresses the campus as a whole and demands different mindsets, skill-sets and delivery. In the HE environment, these changes are difficult to implement due to the difficulty of achieving meaningful engagement with lecturers in the process. To achieve successful implementation of a large-scale change such as internationalisation, HEIs have to focus on the human factors involved and have a clear understanding of the academic cultures that pertain (Storberg-Walker \& Torraco, 2004). However, to date, limited studies have utilised change management theories to support IoC efforts (Crosling et al., 2008; Leask, 2013). Existing research has also not honed in on the challenges to lecturers of adding an international dimension to their T\&L environment or on understanding their overall engagement with the process in their everyday teaching practice.

Due to the fact that IoC is a transformational change and to respond to the need to prioritise lecturers' perspectives in the process, Change Theory (CT) was adopted as the overarching theoretical perspective for this study. In general, CT is defined as a 'predictive assumption about the relationship between desired changes and the actions that may produce those changes' (Connolly \& Seymour, 2015, p. 1).

To date little attention has been given to strategies to bring about change within the context of internationalisation of higher education. This study focused on CT relevant to planned change in an education context, and Action Research (AR) was the selected change model. In the university context, change management tends to be 'collective, planned and evolutionary', which lends itself to AR (Crosling et al., 2008, p. 110). This study's main influence was the 'IoC in Action' project (Leask, 2013) and it was recontextualised to suit the Irish context which is at a much earlier stage of the internationalisation process. In addition, a CoP was developed to facilitate the AR process and related discussions. The CoP provided the space to effect change at an individual, T\&L and 
institute-wide level (Killbride et al., 2011). Leask (2013) developed 'critical interdisciplinary spaces' which informed this study's CoP model. No studies to date, in the Irish context and very few internationally, have reported on the CPL process for engaging lecturers with IoC.

This study aims to respond to calls in international literature for more research that prioritises the lecturers' perspectives on IoC (Hoff \& Gobbo, 2019; Kirk et al., 2018; Leask, 2013) and for alternative approaches to CPL for IoC (Green \& Whitsed, 2015). More specifically, it aims to expand on the research in the Irish context by providing a picture of lecturers' engagement with IoC in the Irish HEIs.

\section{Methodology}

\section{Semi structured interviews: design and considerations}

Semi-structured interviewing is a flexible method of gathering information and opinions. It allows the interviewer to expand on participants' answers and subsequently responses can be analysed and interpreted to recognise common trends or distinctive views (Drever, 2003). The interviews were conducted to gather qualitative data relating to the CoP participants' understanding of, and engagement with IoC based on their actual experiences before and after their engagement with the $\mathrm{CoP}$ in order to answer the RQs.

With the participants' permission the interviews were recorded. The key topics and questions to be discussed were listed thematically in the interview schedule, allowing room for divergence if required (Drever, 2003). The semi-structured interview questions were predominately open-ended and designed to reveal behaviours and experiences associated with the overall aims of the RQs. A series of prompts and probes were utilised to encourage participants to answer questions and to allow space for elaboration (Drever, 2003). To ensure participants could absorb the information, short and straightforward questions were used for the interview schedule. After each interview, contact summary forms are used to capture the main concepts, themes, issues and questions that emerged from the interviews and to highlight which RQs were predominantly addressed (Miles \& Huberman, 1994). Full ethical approval was received from TU Dublin Ethical Committee in advance of this study. Participants completed a consent form in advance of the interview. Confidentiality was also guaranteed.

\section{Action research informed community of practice: design and considerations}

At its core, AR focuses on simultaneous action and research in a simultaneous manner (Zuber-Skerritt \& Perry, 2002). AR provided a framework to conduct an analysis of the participants' engagement with IoC and hence helped with further understanding the implementation gap between theory and practice surrounding IoC. Subsequently it provided a framework to support and motivate participants to embed IoC into their curricula. The AR process both revealed the practical strategies the participants used to internationalise their curricula and practical knowledge regarding the researcher's observations on the benefits and constraints of using a CoP to engage lecturers with curriculum innovations such as IoC. In addition, a CoP was used as the platform for discussion, 
collaboration and change. Through peer learning and collaboration, Communities of Practice foster change (Killbride et al., 2011).

Volunteer lecturers from the four core discipline areas, namely engineering, science, business and humanities, were invited to participate in an IoC:CoP. As AR, in principle, offers a tangible reward, namely the potential improvement of T\&L strategies, it was hoped that this would attract lecturers. It was also an opportunity to work in a heterogeneous group with lecturers who would have many varied experiences to share. Eight volunteers were identified from across TU Dublin and represented a range of disciplinary backgrounds.

The researcher conducted semi-structured interviews with the participants initially to further set the context and understand their current level of understanding of and engagement with IoC. The RQs informed the interview question design. Participants then engaged with five CoP discussions over the period of one academic semester, which reflected the five phases of an $\mathrm{AR}$ cycle that is detailed in Figure 1. Interviews were also conducted post CoP to allow for comparison of pre and post CoP data and to address RQ 3.

The time points of the IoC:CoP process are as follows:

Time point 1: Pre CoP Interviews

Time point 2: CoP 1 - Review \& Reflect

Time point 3: CoP 2 - Imagine

Time point 4: CoP 3 - Revise \& Plan

Time point 5: CoP 4 - Act

Time point 6: CoP 5 - Evaluate

Time point 7: Post CoP Interviews

Throughout one semester, the participants engaged in CoP discussions that reflected the five phases of the AR core cycle, see Figure 1 which is explained next.

\section{loc: CoP model}

The AR model adopts Zuber-Skerritt and Perry's (2002) thesis and core cycles, which operate in parallel. The thesis cycle involved the following phases:

- Planning - conducting the situational analysis of the current level of IoC engagement.

- Acting - establishing the cross-disciplinary IoC: CoP, and calling for volunteers to participate. Volunteers were interviewed before joining the CoP.

- Observing - observing the CoP process and how participants' understanding and engagement evolved over time.

- Evaluating - evaluating the $\mathrm{CoP}$ process and conducting the post $\mathrm{CoP}$ interviews.

The core cycle was informed by the Leask's (2013) IoC in Action Project, which argues that IoC should be a planned, developmental and cyclical process. It involved the participants engaging with the following five phases in an attempt to incorporate IoC dimensions into their T\&L: 


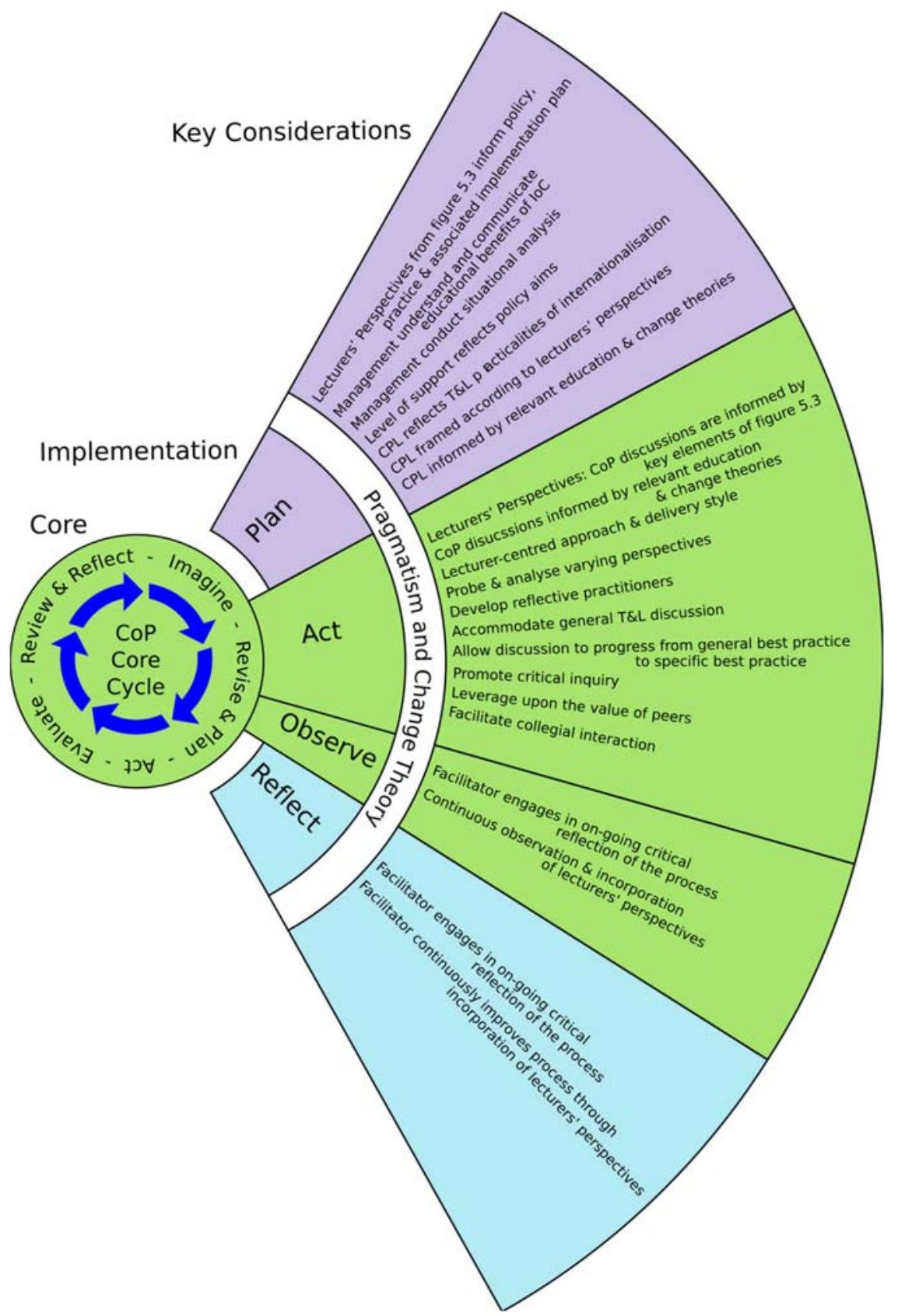

Figure 1. Internationalisation of the curriculum: community of practice model (researcher's own).
(1) Review \& Reflect
(2) Imagine
(3) Revise \& Plan
(4) Act
(5) Evaluate 
Consistent with CT, this study drew from Pragmatic AR (Greenwood \& Levin, 2007), Participatory AR (Reason, 2004) and Collaborative AR (Manesi \& Betsi, 2013) modalities, all of which prioritise the lecturers' perspectives and foster a culture of support for IoC amongst enthusiasts and in turn the mainstream population (Kotter, 2007).

\section{Change theories}

In addition to utilising $\mathrm{AR}$ as the change model to engage lecturers with IoC, other change theories, relevant in the HE context were also considered to make the AR model more robust. Schon's (1991) Theory of the Reflective Practitioner and Argyris and Schon's (1974) Theory of Double Loop Learning both facilitate change and were incorporated throughout the CoP process. The researcher and lecturers reflected both in action and on their actions which resulted in attitudinal and behavioural change. This is representative of double-loop learning which is essential to bring about change (Argyris \& Schon, 1974). Furthermore Lewin's (1948) three step change model of 'being motivated to change, changing and making the change survive and work' informed the CoP process. The collaborative, reflective, participatory CoP model supports the key tenets of the change theories mentioned above.

\section{IOC: CoP- sequence of events}

Prior to the commencement of the $\mathrm{CoP}$, the volunteers were invited to attend the $\mathrm{CoP}$ discussions via an online scheduling tool. CoP discussions were scheduled for $1.5 \mathrm{~h}$. Dates and times were selected to suit the majority. If participants could not attend, they were encouraged to share their input via the associated Google Drive. This platform stored the information relating to the CoPs to ensure participants were informed at all times.

Table 1 below summarises the key stages of the CoP process. While this study was specific to TU Dublin and the participants who volunteered, the detailed description of events allows for transferability to other contexts (Creswell, 2013). The reader is advised to interpret to suit their own HE context.

\section{Data analysis}

This study was an exploratory process which aimed to generate themes to further understand how lecturers understand and engage with $\mathrm{IoC}$ in their respective contexts. The priority was to give a voice to lecturers as this has typically not been done in studies to date (Green \& Whitsed, 2015; Hoff \& Gobbo, 2019; Kirk et al., 2018; Leask, 2013). Furthermore, it sought to reveal new knowledge of how their engagement evolved over time and what supports they need to achieve their goals.

Thematic analysis of the interviews and CoP data was conducted using Braun and Clarke's (2013) six phase thematic analysis together with the NVivo coding management system. Braun and Clarke (2013) define thematic analysis as a means of identifying themes and patterns of meaning from across a data set, in relation to RQs. The analytic interest in this study was lecturers' perspectives of IoC and its associated implementation into the T\&L context. 
Table 1. Internationalisation of the curriculum: community of practice time points and associated activities.

\begin{tabular}{|c|c|}
\hline $\begin{array}{l}\text { CoP time } \\
\text { point }\end{array}$ & Activity \\
\hline Pre- CoP 1 & $\begin{array}{l}\text { Participants received loC related pre-readings to inform their thinking and lay the foundation for their } \\
\text { engagement with the CoP. }\end{array}$ \\
\hline CoP 1 & $\begin{array}{l}\text { Discussion in relation to the 'Review \& Reflect' phase of AR cycle as per Figure 1. Participants considered } \\
\text { their rationales for internationalising the curriculum, their conceptualisations of loC and their } \\
\text { approaches to loC. The researcher facilitated the brainstorming session and captured the participants' } \\
\text { ideas on flip chart paper. }\end{array}$ \\
\hline Post-CoP 1 & $\begin{array}{l}\text { After CoP 1, participants received a summary of outcomes generated in CoP } 1 \text { which were compiled by } \\
\text { the researcher. They also received best practice guides and a template to inform their input to CoP } 2 \text {. }\end{array}$ \\
\hline CoP 2 & $\begin{array}{l}\text { Discussion in relation to the 'Imagine' phase of AR cycle. Participants shared new ways of thinking and } \\
\text { approaching loC through translating the rationales and conceptualisations of CoP } 1 \text { into loC curriculum } \\
\text { change using the approaches they had established together. The researcher recorded the ideas on flip } \\
\text { chart paper. }\end{array}$ \\
\hline Post-CoP 2 & $\begin{array}{l}\text { Participants received a summary of the outcomes generated in CoP } 2 \text { which were compiled by the } \\
\text { researcher and were encouraged to revise the ideas they had shared, and plan and document their } \\
\text { steps on how to implement loC into their module of choice, prior to CoP } 3 \text {, using the template } \\
\text { provided. }\end{array}$ \\
\hline CoP 3 & $\begin{array}{l}\text { Discussion in relation to the 'Revise \& Plan' phase of AR cycle. Participants discussed how they planned to } \\
\text { do things differently in their modules with regards to loC. Participants shared their action plans to } \\
\text { practically implement their loC learning activities and shared ideas for measuring the impact on } \\
\text { students' learning. The researcher facilitated the discussion, guiding and supporting where necessary. }\end{array}$ \\
\hline Post CoP 3 & $\begin{array}{l}\text { Participants received a summary of the outcomes generated in CoP } 3 \text { which were compiled by the } \\
\text { researcher and were asked to trial their activities in class before CoP } 4 \text {. They had approximately } 5 \\
\text { weeks to do this. }\end{array}$ \\
\hline CoP 4 & $\begin{array}{l}\text { Discussion in relation to the 'Act' phase of AR cycle. Participants shared their progress, challenges and/or } \\
\text { successes with regards to the new loC activities they were trialling in their classes and reflected on how } \\
\text { they planned to change their approach and methodology for the remainder of the semester. }\end{array}$ \\
\hline Post CoP 4 & $\begin{array}{l}\text { Participants received a summary of the outcomes generated in COP } 4 \text { \& were asked to continue trialling } \\
\text { their activities for the remainder of the semester, which was another } 5 \text { weeks. }\end{array}$ \\
\hline CoP 5 & $\begin{array}{l}\text { Discussion in relation to the 'Evaluate' phase of AR cycle. Participants evaluated the extent to which they } \\
\text { felt they achieved their loC goals, reflected on the impact of the action taken and discussed how they } \\
\text { would approach their T\&L differently in the future. They also discussed ways they could share the } \\
\text { outcomes of this project with a wider audience. }\end{array}$ \\
\hline Post CoP 5 & Participants received a summary of the outcomes generated in CoP 5. \\
\hline
\end{tabular}

Braun and Clarke's (2013) thematic analysis involved the following phases:

(1) Familiarising oneself with the data

(2) Generating initial codes

(3) Searching for themes

(4) Reviewing themes

(5) Defining and naming themes

(6) Producing the report

The findings from the analysis of the interviews and CoP discussions (referred to as CoP data hereafter) are discussed next.

\section{Findings}

\section{Cop participants' understanding of and engagement with IoC}

Upon extensive analysis of the CoP data using Braun and Clarke's (2013) thematic analysis, the following four themes were identified in relation to RQ2 1 and 2, the participants' understanding of and engagement with IoC: 
Theme 1: Willingness to engage with IoC

Theme 2: Recognition of the Value of IoC

Theme 3: Incorporation of IoC into T\&L Strategies

Theme 4: Perceived Barriers to IoC

\section{Theme 1: willingness to engage with loC}

While the CoP participants did not display an in-depth knowledge of the concept of IoC, their input to the CoP discussions suggests an innate understanding, perceived responsibility and willingness to engage with the topic. Furthermore, after running a query in NVivo to analyse this theme across the key time points of the study, it revealed that references to narrow conceptualisations of IoC such as mobility were significantly higher in the earlier stages of the process (time point 1) when compared to the latter stages (time point 7). Once discussions were redirected to the practicalities of internationalisation for the T\&L environment, these narrow associations with IoC were not raised. Similarly, there were notably less references to the participants' stereotypical thinking associated with international students' learning abilities in the later stages. As the CoP progressed, participants broadened their view of international students and focused more on what students do rather than who they are.

An examination of the CoP data indicated that participants frequently acknowledged the more culturally diverse cohorts they are experiencing and their awareness of a need to adapt teaching to address this change, as the following quote illustrates:

Based on last year, I'd say approximately $75 \%$ have some other culture, whether it be Erasmus or, the recent Irish shall we say. And they may have been here 10 years or 20 years and their parents may have another culture. (CoP 1)

Another recurrent theme was their observation of the lack of integration between international and domestic students and a perceived insularity of the Irish students.

So they're sitting in the same class as Erasmus students and they don't talk to them, they don't ask them where are you from, why did you come here, what do you think of us. (CoP 1)

The participants presented a good level of understanding of the need to enact curriculum change in the face of the diversifying student cohort and felt it was their duty as lecturers to prepare students to be global citizens. After running a query in NVivo, it was clear that there was a perceptible increase in the participants' references to the role of IoC in addressing inclusivity and accessibility in their curricula as the study progressed (Figure 2).

\section{Theme 2: recognition of the value of IoC}

The analysis showed that all participants recognised the educational value of IoC and there was a noticeably higher level of discussion surrounding the topic as the CoP sessions progressed. Some of the benefits of IoC that the participants referenced included:

- Association of IoC with graduate attributes and developing students to be global citizens for a global workplace. 


\section{Inclusivity \& Accessibility as key rationales for loC}

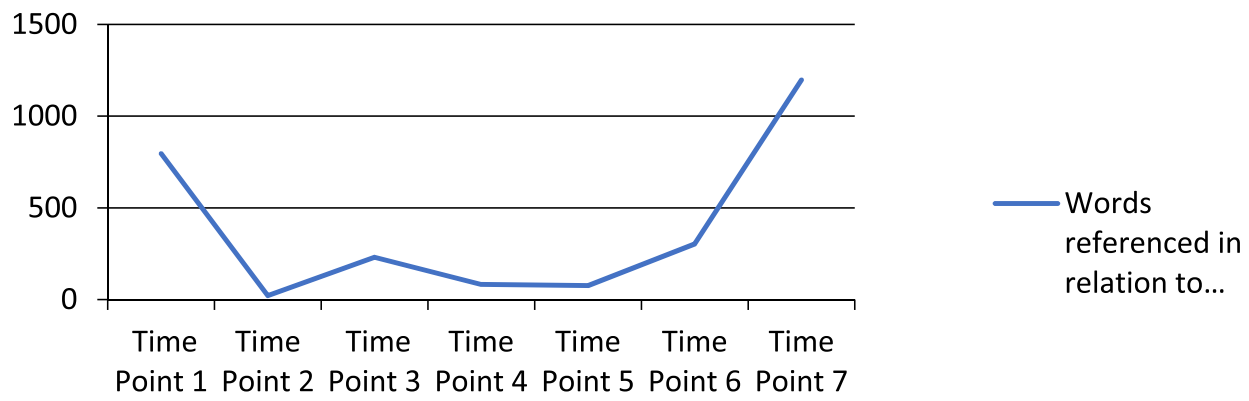

Figure 2. Inclusivity and accessibility as key rationales for loC as referenced across the time points of the study.

- Opportunity for students to integrate and build relationships with students from diverse cultural backgrounds.

- Opportunities for lecturers to engage with students in different ways.

- Tangible benefits of IoC: participants referenced improved dynamic in their classes and more engaging and interesting discussions.

- Relevance of IoC to all students. Participants referenced this significantly more in the later phases, the following quote summarises their opinions regarding the topics: Well in a nutshell, what it does for me I find is it adds another dimension and both for myself and for the non-international students and obviously the international students as well and it allows us explore beyond our own horizons here and that's really important. (Post CoP Interview)

\section{Theme 3: incorporation of IoC into T\&L strategies}

From the beginning of the process, the analysis revealed how participants displayed their awareness of using cultural diversity as a teaching resource. It was, however, predominantly from the 'Acting' phase of the AR cycle when participants started to share specific lesson activities, interalia, facilitating cross-cultural groups or introducing opportunities for students to reflect on the role culture plays in their discipline. This suggests that while they were conscious of the need to adapt their teaching, they had not considered the practicalities prior to their engagement in the CoP.

\section{Theme 4: perceived barriers to loC}

Upon analysis of the CoP data, it was evident that as the participants tried to incorporate practical IoC strategies into their T\&L, they increasingly acknowledged the complexity and associated challenges.

The participants' concerns regarding the time and effort demanded to engage with student-centred activities such as IoC were consistent. They also commented on more practical challenges such as the difficulty of knowing who your international students are and the challenge of integrating with international and domestic students. At an 
institutional level, the most commonly cited barriers were the lack of management support and a perception that management did not recognise the educational values of internationalisation. They repeatedly noted in differing forms that management have never discussed it with anybody' (CoP1).

\section{The role of the COP in influencing engagement with IoC}

In response to RQ 3, the CoP data was also analysed extensively from the perspective of the CoPs' potential influence on engaging lecturers with IoC. The following theme emerged:

Theme 5: CoP is a Platform for T\& L Change.

\section{Theme 5: COP is a platform for T\&L change}

A query was run in NVivo to analyse this theme across the time points and showed that from the 'Imagine' phase of the cycle, there was clear evidence from the participants' commentary that they had a heightened awareness of IoC and were more conscious of the cultural diversity in their classes. They demonstrated, through their choice of language, a shift in perspective to a broader understanding that valued its educational benefits. Participants commented that they were actively 'thinking about how they can adapt things' and doing things that they 'wouldn't have done before' as a result of their increased awareness of IoC.

The participants also demonstrated that they had a change in their teaching approach and practice as a result of their participation in the group. This is illustrated in the following quote:

And to a certain extent we were pushed out of our comfort zone and made look at things in a different way and that's very positive (Post CoP Interview)

Furthermore, as was referenced earlier in response to RQ 1, as the CoP progressed, participants further incorporated IoC strategies into their T\&L activities.

An examination of the CoP data also indicated that all participants valued the participatory and reflective nature of the CoP process. They commented favourably on the facilitation style which prioritised taking a lecturer-centred approach. They all commented on the value of working with peers and specifically the cross-disciplinary nature of the CoP. They frequently referenced the value of sharing others' experiences and having the reassurance they were all facing similar challenges regardless of their disciplinary backgrounds.

\section{Discussion of findings}

The findings from this research provided valuable answers to the three RQs and significantly increase the scope of existing theories of IoC.

\section{CoP participants' understanding of and engagement with IoC}

The participants' narrow level of understanding of IoC was broadly similar with findings from the only other empirical study of IoC in the Irish HE context (Clarke et al., 2018) and hence extends the work that has been done to date. While some literature suggests there may be a lack of interest or even a negative perception amongst lecturers of IoC (Clarke et al., 2018; Green \& Mertova, 2011 ; Proctor, 2015), the lecturers in this 
study, demonstrated the contrary. It was evident that IoC was a 'personal' issue for the participants, a view which has not been typically expressed to date in the literature. This 'personal' interest supports the first stage of typical change models, e.g., in Lewin's (1948) three step model of change, step one is 'being motivated to change'. Furthermore, while the participants demonstrated unfamiliarity with the concept of IoC, their input to the CoP discussions suggests an innate understanding and willingness to engage with the topic. It is apparent that HEIs need to be aware of this innate understanding and assist lecturers in moving it to the next level in order to clarify the educational benefits and embed internationalisation at the T\&L level. This study builds on existing studies that have used the perspectives of change management to enhance engagement amongst lecturers with IoC through adopting a lecturer-centred approach (Crosling et al., 2008; Leask, 2013).

The fact that the lecturers in this study volunteered to participate is a limitation of this study. However, while the lecturers in this study may be labelled as 'enthusiasts', it still highlights the importance of HEIs facilitating conscientious lecturers who seek alternative approaches to T\&L. This is consistent with CT, whereby 'enthusiasts' are the starting point to facilitate change institution wide (Kotter, 2007). While this study focused on engaging lecturers with IoC, the findings would conceivably be relevant to engaging lecturers with other best practice teaching initiatives.

The participants expressed their concerns about the changing mentality of Irish students in the context of integration between international and domestic students. They felt there was an apparent disinterest amongst domestic students regarding interacting with their international counterparts. While existing literature discusses the value of conceptualising intercultural diversity as a teaching resource (Dunne, 2013), it has not typically highlighted this concern amongst lecturers or the value of relationship building amongst students which the participants in this study associated with IoC. This new insight was a further motivating factor for the participants to engage with IoC.

Some literature stipulates the need to more explicitly link IoC with equality and diversity policies (Caruana \& Ploner, 2010) and the lecturers in this study concurred. This strengthens the rationale for using lecturers' perspectives to inform policy and practice, which again is consistent with the AR change model adopted in this study (Reason, 2004) and is one of the key attributes of CT (Argyris \& Schon, 1974; Kotter, 2007; Lewin, 1948).

In terms of their engagement, while there is an appreciation of the potential of IoC, the implementation gap still exists, which is consistent with international literature on the subject (Van Gyn et al., 2009). The findings revealed a disparity between the participants' positive attitude towards IoC and their implementation of the process in practice.

While the benefits of using cultural diversity as a resource are cited in the literature (Dunne, 2013), it does not seem to comprehensively discuss the challenges associated with the process in practice. Identifying the international students in the class and facilitating cross-cultural groups were real challenges faced by the participants and have not typically been acknowledged in the best practice guides.

The participants' negative perspectives of the institutional stance of IoC also appeared to be a major contributing factor to the implementation gap. There is clear evidence in the literature that there is a direct correlation between management support and lecturer engagement with IoC (Hellsten, 2007; Proctor, 2015). Because lecturers' perspectives have not been typically collected to date, this study provides new insights into their 
perspective of management and reveals a disparity between what management think they promote and what lecturers perceive.

This study demonstrated the incongruence between espoused theory and theory in use at both management and lecturer level. If management are aware of lecturers' perspectives, it could inspire change in how IoC is communicated at institutional level.

\section{The role of the COP in influencing engagement with IoC}

There has been little consideration to date in the IoC literature regarding the incorporation of CT to enhance the uptake of IoC (Crosling et al., 2008; Leask, 2013; Van Gyn et al., 2009). The findings in this study supported the principles of CT and demonstrated, through an innovative approach, empirical evidence of its value in the CPL process. CT prioritises the key stakeholders responsible for enacting the change and hence reveals what approach HEIs should be taking to address IoC implementation. The IoC literature discusses the importance of staff engagement for successful implementation (Kirk et al., 2018; Leask, 2013; Van Gyn et al., 2009) and this study adds to that literature.

Initially the participants defaulted to general T\&L-related discussions rather than IoCspecific methodologies. It could be argued that the CoP was addressing deficiencies in the T\&L-related CPL that lecturers had been exposed to to date. It also highlighted the importance of HEIs facilitating discussions on general best practice T\&L while simultaneously introducing IoC under this broader umbrella. This supports the premise that at its core, IoC is essentially best practice teaching (Clifford, 2013; Van Gyn et al., 2009). Furthermore, it highlights the value of incorporating change theories to facilitate reflection and double-loop learning amongst lecturers (Argyris \& Schon, 1974).

The IoC-related activities trialled by the participants predominantly focused on cross-cultural groups and reflective activities. Regardless of the extent to which the participants trialled IoC activities, they all commented on the influence of the CoP to motivate them to engage in new teaching methodologies. While this finding is understandable, as IoC is in an early developmental stage in the Irish HE context, it is also relevant to the field of best practice teaching generally. It highlights the challenges of engaging with student-centred pedagogy and the supports HEIs need to provide. The lack of attention given to T\&L-related initiatives in HEIs is echoed in the literature (Robson et al., 2013).

There were also some unpredicted and beneficial spin-off activities resulting from the IoC:CoP due to the participants' desire to disseminate their learnings with colleagues, i.e., an IoC- related funding proposal. This supports the important role of enthusiasts in the CT process (Kotter, 2007).

\section{Conclusion and recommendations}

The purpose of this study was to advance the conceptualisation of IoC and to understand the implementation gap between theory and practice by exploring the topic from lecturers' perspectives. Furthermore, it aimed to use CT to establish a CPL model in an attempt to enhance engagement and effect change. The following three recommendations will be of interest in the broad field of internationalisation of $\mathrm{HE}$ and, specifically, 
they will be important to both educational management and T\&L development centres who are endeavouring to embed internationalisation at T\&L level.

(1) HEIs should incorporate lecturers' perspectives into both the design and communication of their internationalisation strategy, policy documents and related CPL.

(2) HEIs should provide lecturers with the space and time to reveal the incongruence between policy and practice, and in turn help them to bridge the gap.

(3) CT should inform IoC policy development and the associated implementation plan.

This is the first study of its kind that utilises CoPs and AR to engage lecturers with IoC in Irish HEIs and one of few studies internationally that addresses IoC using this methodology. It is believed that this overall approach to IoC would effectively accelerate engagement with the process and help achieve sustainable change in the area of internationalisation. While the findings are unique to this HE context, the CoP approach used could also conceivably be applied in other institutional contexts and bears relevance to best practice T\&L in general.

Through exploring CT in the context of IoC, it gave new insights into the required CPL. The role of CT, lecturers' perspectives and critical and collaborative CoPs all emerged as key characteristics important for effectively engaging lecturers with IoC.

Additional research involving other participants and conducted in other HE contexts would be necessary to verify the findings.

\section{Disclosure statement}

No potential conflict of interest was reported by the authors.

\section{ORCID}

Deirdre Ryan (D) http://orcid.org/0000-0002-0512-5369

\section{References}

Argyris, C., \& Schon, D. (1974). Theories in practice: Increasing professional effectiveness. Bassey.

Braun, V., \& Clarke, V. (2013). Successful qualitative research, a practical guide for beginners. Sage Publications.

Caruana, V., \& Ploner, J. (2010). Internationalisation and equality and diversity in higher education: Merging identities. Retrieved May 20, 2017, from http://eprints.leedsbeckett.ac.uk/600/ 1/internationalisation-equality-diversity-in-he.pdf

Clarke, M., Yang, L., \& Harmon, D. (2018). The internationalisation of Irish higher education. Higher Education ity.

Clifford, V. (2013). The elusive concept of internationalistaion of the curriculum. Retrieved November 15, 2015, from https://www.brookes.ac.uk/services/cci/definitions.html

Clifford, V., \& Montgomery, C. (2011). Ch 1 introduction: Internationalizing the curriculum for global citizenship in higher education. In V. Clifford, \& C. Montgomery (Eds.), Moving towards internationalisation of the curriculum for global citizenship in higher education. OCSLD, Oxford Brookes University. Retrieved November 15, 2015, from https://www.brookes.ac.uk/ services/ cci/definitions.html

Connolly, M. R., \& Seymour, E. (2015). Why theories of change matter. Retrieved August 15, 2017, from https://files.eric.ed.gov/fulltext/ED577054.pdf 
Creswell, J. W. (2013). Qualitative inquiry \& research design choosing among five approaches (3rd ed.). Sage.

Crosling, G., Edwards, R., \& Schroder, B. (2008). Internationalizing the curriculum: The implementation experience in a faculty of business and economics. Journal of Higher Education Policy and Management, 30(2), 107-121. https://doi.org/10.1080/13600800801938721

DoES. (2016). Irish educated globally connected. An international education strategy for Ireland, 2016-2020. Retrieved January 12, 2017, from https://www.education.ie/en/Publications/ Policy-Reports/International-Education-Strategy-For-Ireland-2016-2020.pdf

Drever, E. (2003). Using semi-structured interviews in small scale research: A teacher's guide. University of Glasgow the SCRE Centre.

Dublin Technology University Alliance (DTUA). (2014-2016). Retrieved March 27, 2017, from https://www.tu4dublin.ie/contentfiles/publications/Dublin\%20Technological\%20University\% 20Alliance\%20Progress\%20Report\%202014\%20-\%202016.pdf

Dunne, C. (2013). Exploring motivations for intercultural contact among host country university students: An Irish case study. International Journal of Intercultural Relations, 37(5), 567-578. Retrieved April 29, 2015, from http://www.sciencedirect.com/science /article/pii/ S0147176713000758. https://doi.org/10.1016/j.ijintrel.2013.06.003

Green, W., \& Mertova, P. (2011). Engaging with the gatekeepers: Faculty perspectives on developing curriculum for globally responsible citizenship. In V. Clifford, \& C. Montgomery (Eds.), Internationalisation of the curriculum for global citizenship: Policies, practices and pitfalls (pp. 69-91). Oxford Centre for Staff and Learning Development (OCSLD) Press.

Green, W., \& Whitsed, C. (2015). Introducing critical perspectives on internationalising the curriculum. In W. Green \& C. Whitsed (Eds.), Critical perspectives on internationalising the curriculum in disciplines (pp. 3-22). Sense Publishers.

Greenwood, D. J., \& Levin, M. (2007). Introduction to action research: Social research for social change (2nd ed.). Sage Publications.

Hellsten, M. (2007). International student transition: Focusing on researching international pedagogy for educational sustainability. International Education Journal: Comparative Perspectives, 8 (3), 79-90.

Henard, F., Diamond, L., \& Roseveare, D. (2012). Approaches to internationalisation and their implications for strategic management and institutional practice. Retrieved February 12, 2015, from http://www.oecd.org/edu/imhe/Approaches\%20to\% 20internationalisation\%20-\%20final \%20-\%20web.pdf

Hoff, J., \& Gobbo, L. D. (2019). The need to approach internationalization as an ecosystem to achieve global learning, in mind the gap. Elon University.

Jones, E. (Ed.). (2010). Internationalisation and the student voice higher education perspectives. Routledge.

Killbride, C., Perry, L., Flatley, M., Turner, E., \& Meyer, J. (2011). Developing theory and practice: Creation of a community of practice through action research produced excellence in stroke care. Retrieved February 5, 2017, from https://www.ncbi.nlm.nih.gov/pmc/articles/PMC3055714/

Kirk, S. H., Newstead, C., Gann, R., \& Rounsaville, C. (2018). Empowerment and ownership in effective internationalisation of the higher education curriculum. Retrieved March, 5, 2018, from https://link.springer.com/article/10.1007/s10734-018-0246-1\#citeas

Kotter, J. P. (2007). Leading change why transformation efforts fail. Harvard Business Review (pp. 96-103). Retrieved February 17, 2018, from https://eoeleadership.hee.nhs.uk/sites/ default/files/leading_change_why_transformation_efforts_fail.pdf

Leask, B. (2009). Using formal and informal curricula to improve interactions between home and international students. Retrieved January 15, 2016, from http://site.valenciacollege.edu/inz/ library/INZ\%20the\%20urriculum/Using\%20Formal\%20and\%20Informal\%20Curricula\%20to\% 20Improve\%20Interactions\%20Between\%20intl\%20and\%20domestic\%20students\%20 (Leask).pdf

Leask, B. (2011). Assessment, learning, teaching and internationalisation - engaging for the future. Retrieved August 27, 2015, from http://eprints.leedsbeckett.ac.uk/1191/1/Assessment\%2C\% 20learning\%2C\%20teaching\%20and\%20internationalisation.pdf 
Leask, B. (2013). Internationalisation of the curriculum and the disciplines: Current perspectives and directions for the future. Journal of Studies in International Education, 17(2), 99-102. https://doi.org/10.1177/1028315313486228

Lewin, K. (1948) Resolving social conflicts and field theory in social science American Psychological Association.

Manesi, S., \& Betsi, S. (2013). Collaborative action research projects: The role of communities of practice and mentoring in enhancing teachers' continuing professional development. Action Research in Education, 4, 109-121.

Miles, M. B., \& Huberman, A. M. (1994). Qualitative data analysis. Sage Publications.

Proctor, D. (2015). Faculty and international engagement: Has internationalization changed academic work? International Higher Education, 83(83), 15-17. https://doi.org/10.6017/ihe.2015. 83.9082

Reason, P. (2004). Action research: Forming communicative space for many ways of knowing. Retrieved April 16, 2017, from http://www.peterreason.eu/Papers/DhakaFormingCommunicativeSpaces.pdf

Robson, S., Wall, K., \& Lofthouse, R. (2013). 'Raising the profile of innovative teaching in higher education? Reflections on the EQUATE project. International Journal of Teaching and Learning in Higher Education, 25(1), 92-102.

Ryan, D., Faulkner, F., Dillane, D., \& Flood, R. V. (2019). 'A situational analysis of the current level of lecturers' engagement with internationalisation of the curriculum in Ireland's first technological university. Retrieved September 19, 2019, from https:/www.tandfonline.com/eprint/ AKSCVI2CJTF4NCYI9DZJ/full?target $=10.1080 / 03323315.2019 .1663551$

Schon, D. A. (1991). The reflective practitioner. How professionals think in action. Ashgate Arena. Storberg-Walker, J, \& Torraco, R. (2004). Change and Higher Education: A Multidisciplinary Approach. Retrieved January 8, 2017, from https://files.eric.ed.gov/fulltext /ED492430.pdf

Van Gyn, G., Caws, C., Lehr, S., \& Preece, A. (2009). Education for world-mindedness: Beyond superficial notions of internationalization. New directions for teaching and learning, 118. Retrieved February 5, 2017, from https://www.researchgate.net/profile/Catherine_Caws/ publication/230409918_Education_for_worldmindedness_Beyond_superficial_notions_of_ internationalization/links /00b4952cdb23ab310f000000.pdf

Zuber-Skerritt, O., \& Perry, C. (2002). Action research within organisations and university thesis writing. The Learning Organization, 9(3), 171-179. https://doi.org/10.1108/09696470210428895 